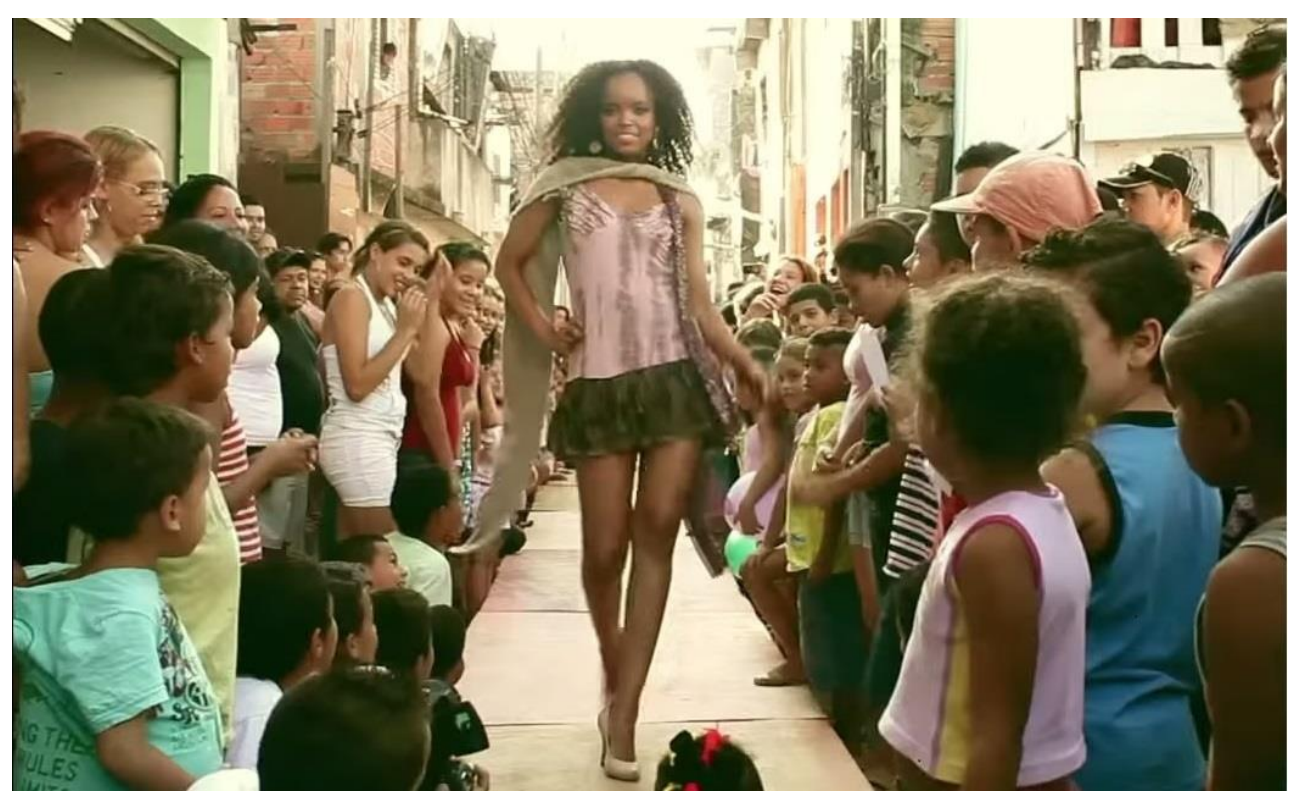

\title{
Memória, narrativa urbana e favela: efeitos de sentido em um videoclipe*
} Memory, urban narrative and favela: effects of meaning in a videoclip

\section{Lucia M. A. Ferreira** Andréa Rodrigues ${ }^{* * *}$}

\section{Resumo:}

No ciberespaço ecoam diariamente textos e imagens que constroem representações da cultura da periferia até bem pouco tempo quase invisíveis na mídia hegemônica. Neste trabalho, são investigadas manifestações dessa narratividade em um vídeo veiculado em um portal das comunidades do Rio de Janeiro. Do campo da linguagem e da memória são investigadas as redes de memória, as marcas da inscrição sócio-histórica do sujeito, assim como os movimentos que faz ao tomar o seu lugar no discurso.

Palavras-Chave: narrativa urbana; videoclipe; memória.

\section{Abstract:}

In the cyberspace can be found the daily echoes of texts and images that produce representations of peripheral culture, up to a very recent past almost invisible to the hegemonic media. This paper examines manifestations of this narrativity in a videoclip exhibited on the Web site of communities (favelas) of Rio de Janeiro. From the perspective of language and memory, we investigate the memory networks, the marks of the socio-historical inscription of the subject and the movements made as he takes his place in discourse.

Keywords: urban narrative; videoclip; memory.

\footnotetext{
* Trabalho vinculado ao projeto "Discurso, sujeito e memória nas tramas dos sentidos sobre o Rio de Janeiro", desenvolvido pelo grupo de pesquisa Discurso e Cidade, no PPGMS-UNIRIO, com apoio do Edital MCT/CNPq/MEC/CAPES no. 02/2010. Versões anteriores foram apresentadas no XXVII ENANPOLL, 2012 e no I CONINTER, 2012. O texto foi parcialmente publicado nos anais do I CONINTER, 2012

** Doutora em Linguística, UFRJ; Docente do Programa de Pós-Graduação em Memória Social- PPGMS - UNIRIO; 1maf@ connection.com.br, Av. Pasteur 458, Rio de Janeiro, CEP 22290-255.

*** Doutora em Linguística, PUC-RJ; Docente do Departamento de Letras da Faculdade de Formação de Professores da UERJ; andrearodrigues.letras@ @otmail.com; R. Dr. Francisco Portela, 1470, São Gonçalo, CEP 24435-005, RJ.
} 


\section{Introdução}

As narrativas urbanas são criadas a partir de processos pelos quais os sujeitos formulam sentidos e os estruturam da maneira como os espaços da cidade os afetam (ORLANDI, 2001). Elas selecionam, atravessam e organizam lugares, criando o que Certeau (2004) chama de "teatro de ações", onde práticas sociais são autorizadas e fundadas.

Certeau toma o ato de caminhar pela cidade como um ato de enunciação em que o caminhante se apropria do sistema topográfico da mesma maneira que o falante se apropria da língua. Se tomados em sua dimensão significativa, o caminhar e o falar encontram seus pontos de convergência e, mencionando uma certa 'retórica da caminhada', o autor nos fala dos relatos de espaço. Nessa perspectiva, no espaço de memória em que esses relatos se inscrevem, são textualizados sentidos sobre o sujeito e sua relação com o espaço e os objetos simbólicos que o circundam.

Os vestígios dessa formulação de sentidos a partir do modo como a cidade afeta os sujeitos podem ser captados nas diferentes materialidades em que a narratividade urbana se manifesta. $\mathrm{Na}$ era do virtual, a rede vem propiciando o surgimento e a circulação de novos sentidos para o urbano. A cultura da periferia e de outras minorias, até bem pouco tempo vista como marginal, quase invisível na mídia hegemônica, dá-se a conhecer na rede. Lembrando, com Orlandi, que o sentido "é janela de que se olha" (2001, p. 10), o presente trabalho tem por objetivo investigar alguns desses sentidos sobre a cidade no videoclipe Favela Fashion Week, veiculado em um portal das comunidades do Rio de Janeiro ${ }^{1}$. Do campo da linguagem e da memória são analisados, no entrecruzamento entre as diferentes materialidades que se manifestam nesses espaços (imagem, texto, música), o movimento dos sentidos, as redes de memória, as marcas da inscrição sócio-histórica do sujeito, os movimentos e a trajetória que faz ao tomar o seu lugar no discurso.

O portal Voz das Comunidades congrega sete comunidades da cidade do Rio de Janeiro. Comporta seções para eventos, datas comemorativas, notícias, curiosidades, esporte, vídeos, galeria de fotos e exibe anúncios veiculados pelo Google. Ao examinarmos essas escritas viabilizadas pela tecnologia, pensamos principalmente na emergência de vozes que dificilmente ecoariam nos espaços midiáticos hegemônicos,

\footnotetext{
${ }^{1}$ Portal Voz das Comunidades: http://www.vozdascomunidades.com.br/;

Videoclipe: http://www.vozdascomunidades.com.br/videos/favela-fashion-week-reuniao-de-amigosclipe-oficial
} 
tradicionalmente atravessados pelos discursos dominantes. O discurso é um lugar de luta pelo direito de significar e precisamos entender essas práticas como uma arena de disputas e negociações por esse direito. Se, ao se apropriarem da tecnologia, essas escritas permitem a reiteração de sentidos já estabilizados no imaginário, elas também permitem que se teçam novas redes semânticas sobre a cidade e sobre os sujeitos.

\section{Efeitos de sentido na imbricação de diferentes materialidades significativas}

Consoante Pêcheux (1999, p. 56), “a memória é necessariamente um espaço móvel de divisões, de disjunções, de deslocamentos e de retomadas, de conflitos de regularização... Um espaço de desdobramentos, réplicas, polêmicas e contra-discursos". A memória está, portanto, inscrita na trama dos discursos em circulação, permeável às transformações que ocorrem no tecido sócio-histórico. É nesse sentido que, como afirma Gondar (2005, p. 16-17), retomando Foucault, a memória, tecida por nossos afetos e por nossas expectativas diante do devir, pode se constituir como um foco de resistência e instrumento privilegiado de transformação social: "Recordar, nesse caso, não é somente interpretar, no presente, o já vivido; a escolha do que vale ou não ser recordado funciona como um penhor e, como todo penhor, diz respeito ao futuro."

$\mathrm{Na}$ análise que ora empreendemos, procuramos examinar, na espessura histórica do vídeo, os gestos de interpretação que nortearam sua realização e os efeitos de sentido do acontecimento discursivo que foi sua divulgação no portal Voz das Comunidades. Que silenciamentos podem ser observados? Como funcionam as réplicas, polêmicas e contra-discursos? Como opera o programa de leitura da imagem, do texto e da música no vídeo, com relação à memória da favela e do asfalto?

Por lidarmos com um objeto simbólico materialmente heterogêneo, entendemos que as estruturas materiais distintas que constituem a cadeia significante materializada no vídeo funcionam em composição (LAGAZZI, 2009), fazendo trabalhar, nas suas especificidades e no movimento do seu encontro, a incompletude e a falha constitutivas das materialidades simbólicas. Cabe ressaltar que, nesse contexto, compreendemos a incompletude não como falta de inteireza, mas como algo que não se fecha, que está aberto, como é próprio de processos de significação em diferentes materialidades. Orlandi (2004, p.12) destaca esta dimensão dos processos significativos, que chama de "abertura do simbólico". Apesar de sua vocação para a unicidade, a discrição e a completude, a linguagem precisa conviver com a falta, a falha e o 
equívoco, marcas da relação da materialidade significante com a exterioridade, a história e a memória. Orlandi nos mostra que é na relação tensa e às vezes indefinível entre os dois eixos que constituem o movimento da significação -a paráfrase e a polissemia - que melhor se observa a abertura do simbólico.

O objetivo do exercício de descrição/interpretação que ora empreendemos é observar, na imbricação dos diferentes sistemas significativos que compõem o vídeo - o musical, o verbal e o imagético -, o trabalho da paráfrase e da polissemia, os dois eixos basilares do processo de significação, e as redes de memória que ele convoca. Admitir a abertura do simbólico não significa que o processo de significação não seja administrado, controlado. Como nos lembra Pêcheux, (2002, p. 56), o discurso "não é independente das redes de memória e dos trajetos sociais nos quais ele irrompe ... todo discurso marca a possibilidade de uma desestruturação-reestruturação dessas redes e trajetos".

\section{Narratividade urbana no videoclipe Favela Fashion Week}

Ao propormos uma reflexão acerca de uma narrativa urbana, é preciso considerar que esses relatos se inscrevem em um espaço de memória onde são textualizados sentidos sobre o sujeito e sua relação com o espaço e os objetos simbólicos que o circundam. Se a cidade é construída de modo homogeneizante e transparente na mídia hegemônica, em um discurso sobre o urbano, outras formas de textualização permitem que se percebam flagrantes de uma narratividade que vai além do sobre a cidade, permitindo que se enxergue o espaço silenciado, muitas vezes invisível na mídia, mas onde se inscreve, no simbólico, o real da cidade.

Jeudy (2005, p. 82) nos diz que a fotografia contemporânea procura mostrar o que a cidade parece esconder. Acreditamos que o mesmo possa ser dito acerca do cinema, mas o que se constata é que a cidade em sua fragmentação e totalidade escapa à representação. Como afirma, mais uma vez, Jeudy (2005, p. 81), “a cidade excede a representação que cada pessoa faz dela", se oferecendo e se retraindo segundo a maneira como é apreendida, materializando-se na interseção dos sistemas simbólicos que a significam.

O cinema já produziu um grande número de narrativas em que a favela, seus moradores e a relação com o mundo do asfalto são continuamente des-interpretados e ressignificados. Desde os primeiros filmes em que se destacava a riqueza cultural, 
especialmente a musicalidade da favela em meio à precariedade das condições de vida o filme Orfeu negro de Camus, de 1959, é emblemático nesse aspecto - , até as mais recentes produções do cinema brasileiro - Cidade de Deus, Tropa de elite I e II e Cinco vezes favela: agora por nós mesmos - , incluindo aqui também a recente produção argentina Elefante branco, a favela vem sendo tematizada em narrativas urbanas que fazem emergir uma rede de sentidos em disputa. Espaço de cultura, musicalidade, miséria, violência, injustiça, pacificação, regeneração, beleza. O discurso sobre a favela não é nem poderia ser homogeneizante - vale destacar aqui o que lembra Orlandi (2004, p.29) a respeito da cidade: “(...) nem o social, nem a cidade, em seu real, tem homogeneidade".

Tomamos então o videoclipe que analisamos como um flagrante dessa narratividade urbana, uma cadeia significante que se tece na imbricação de diferentes materialidades, em meio à tensão entre a formulação de sentidos em cada sistema simbólico e a memória. Em sua opacidade, a formulação é atravessada pelo trabalho da ideologia, que torna evidentes sentidos colocados em disputa na memória. Enquanto modalidade do discurso urbano, os sentidos produzidos no clipe funcionam como "flagrantes de um olhar (um corpo) em movimento" (ORLANDI, 2001, p.31). Essas formas de significar são incluídas na própria forma material da cidade. Somente se separam da cidade para funcionar como "lembretes para o exterior". Isso é que cria uma outra forma de narratividade, em que as condições de produção não se destacam dos textos. As narrativas urbanas não têm, assim, um narrador e um conteúdo separados das condições de produção.

No vídeo Favela Fashion Week, aparentemente o clipe promocional do CD Clareou, clareou... do grupo Reunião de Amigos, o próprio espaço é conteúdo do texto. Jacques (2001, p.3), ao abordar a favela como labirinto, observa que

(...) a favela não possuiu uma planta prévia, ela não foi desenhada, projetada. O labirinto-favela (...) não é fixo, acabado, ele está sempre se transformando. Nenhuma planta de favela é definitiva, só podem existir plantas momentâneas, e sempre feitas a posteriori. (...)

O tecido urbano da favela é maleável e flexível, é o percurso que determina os caminhos. Ao contrário da planificação urbana tradicional que determina o traçado a priori, na favela as ruas (e todos os espaços públicos) são determinadas exclusivamente pelo uso.

O clipe mostra um desfile de mulheres, que começa numa espécie de camarim e percorre as vielas da favela - a letra diz: "na favela (...) a viela vira passarela". Se, como propõe Jacques, a favela e suas ruas são determinadas pelo uso, sem planta a priori, 
podemos afirmar que é a própria câmera que, ao fazer o percurso das vielas, vai fazendo existir o tecido urbano da favela, (re)criando esse espaço com a própria narrativa urbana.

As formas do discurso urbano são entrelaçadas de modo a (re)construir o corpo significativo da cidade, da favela: a música, a letra, o cenário da favela e da cidade, o desfile das mulheres pelas ruas estreitas, os olhares dos homens, a dança. São flagrantes de uma narratividade urbana que tem vários pontos de materialização.

Orlandi (2001, p. 31) observa que "quando o espaço é silenciado o espaço responde significativamente". As respostas passam por processos de des-transformação e des-interpretação, produzidas nas diferentes formas do discurso urbano.

Se no passado a favela era discursivizada como espaço de violência, pobreza, marginalidade, hoje ela é "des-interpretada" e transformada em espaço ocupado, pacificado, com novos sentidos. Vale ressaltar no entanto que o discurso, como afirma Pêcheux (2002, p. 56), embora seja "o índice potencial de uma agitação nas filiações sócio-históricas de identificação", é também efeito de um deslocamento no seu espaço.

Esse processo de ressignificação aponta para o que Mariani define como o "futuro dos sentidos", que se baseia no já dito e no dizível de acordo com as "possibilidades enunciativas dos períodos históricos" (MARIANI, 1998, p.28). As políticas públicas de pacificação das favelas do Rio de Janeiro desenvolvidas nos últimos anos articulam-se com as possibilidades enunciativas do momento atual, promovendo um discurso de integração entre morro e asfalto e buscando construir sentidos para o futuro da cidade que acolherá eventos mundiais em 2014 e 2016. O discurso da integração perpassa a fala da moradores, registrada em outros textos disponíveis no Portal - por exemplo, um vídeo que registra um passeio no teleférico do Complexo do Alemão, em que o apresentador, músico conhecido e morador do lugar, afirma: "É isso aí, gente. Complexo do Alemão, pode vim (sic), pode chegar que tá todo mundo convidado, tá todo mundo tranquilo." A integração também é apontada na letra da música do clipe Favela Fashion Week, que recomenda que o ouvinte suba no morro para ver a beleza das mulheres: "sobe lá para você ver". É o discurso da valorização do morro, de interpretações sobre a favela que criam um novo "teatro de ações", no sentido de Certeau (2004), e assim autorizam novas práticas sociais e relações com o espaço e os objetos simbólicos que lá circulam.

É preciso, no entanto, tornar mais visíveis os mecanismos discursivos mobilizados no clipe nessa reconstrução imaginária da favela, de seus habitantes e de 
suas práticas sociais. Lembrando, com Gondar (2005, p.17) que "há sempre uma concepção de memória social implicada na escolha do que conservar e do que interrogar" e que essa escolha envolve uma aposta no futuro, procuramos, na imbricação das diferentes materialidades significativas, as marcas desse discurso.

No clipe, a filiação ao discurso da integração favela-asfalto é marcada pela tensão entre o novo e a tradição, entre a repetição e a reformulação, entre a paráfrase e a polissemia, marcadas na melodia do samba de ritmo cadenciado, fácil, na letra e nas imagens. Nessa perspectiva, a memória do samba empresta ao clipe a contradição que marca a sua trajetória: de manifestação cultural de herança negra, marginalizada no início do século XX, passa a ser símbolo inquestionável da musicalidade do brasileiro.

O equívoco e a contradição se manifestam desde o título da música e do clipe Favela Fashion Week -, um mix linguístico, um híbrido que marca uma posição discursiva que mobiliza duas redes de memória que funcionam de forma dissonante. Os deslizamentos sugeridos pela denominação têm como efeito de sentido a ironia, o deboche. É justamente esta ironia diante da contradição que irá marcar o processo discursivo no vídeo.

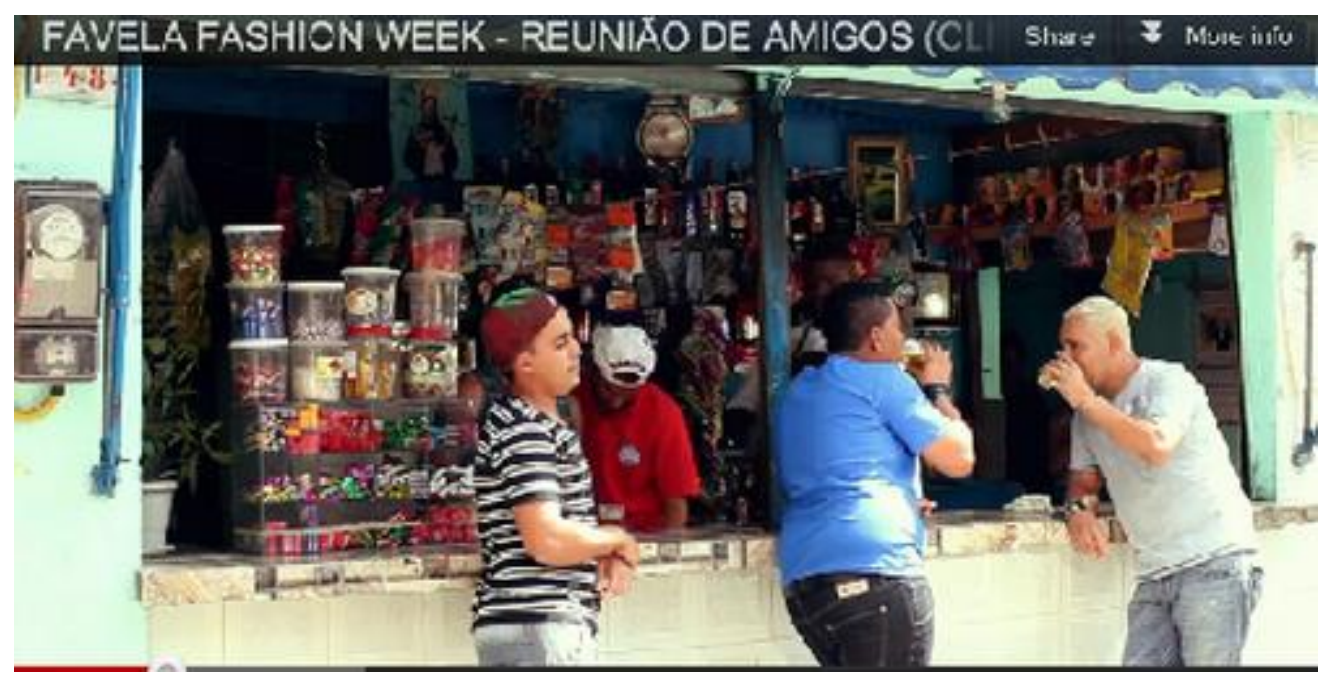

Disponível http://www.vozdascomunidades.com.br/videos/favela-fashion-week-reuniao-deamigos-clipe-oficial

$\mathrm{Na}$ abertura do clipe veiculado no Portal, uma cena do cotidiano da favela: uma birosca e três rapazes tomando cerveja; ao fundo, o vendedor. Há uma interrupção brusca da cena e, em um novo cenário, que representa o backstage de um desfile de modas, o foco da câmera move-se, devagar, de uma fotografia de corpo inteiro de 
Gisele Bündchen para mostrar, em plano fechado, o rosto de uma bela jovem negra que retoca a maquiagem olhando-se no espelho.

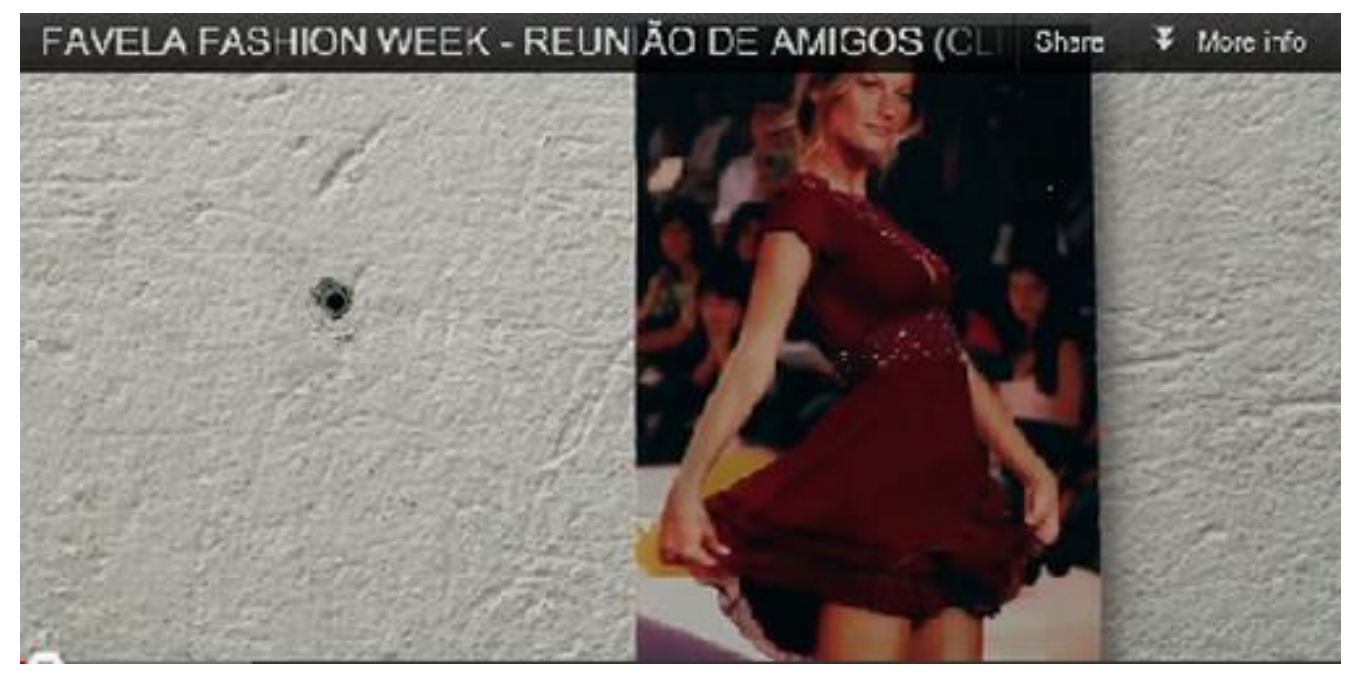

Disponível em http://www.vozdascomunidades.com.br/videos/favela-fashion-week-reuniao-deamigos-clipe-oficial

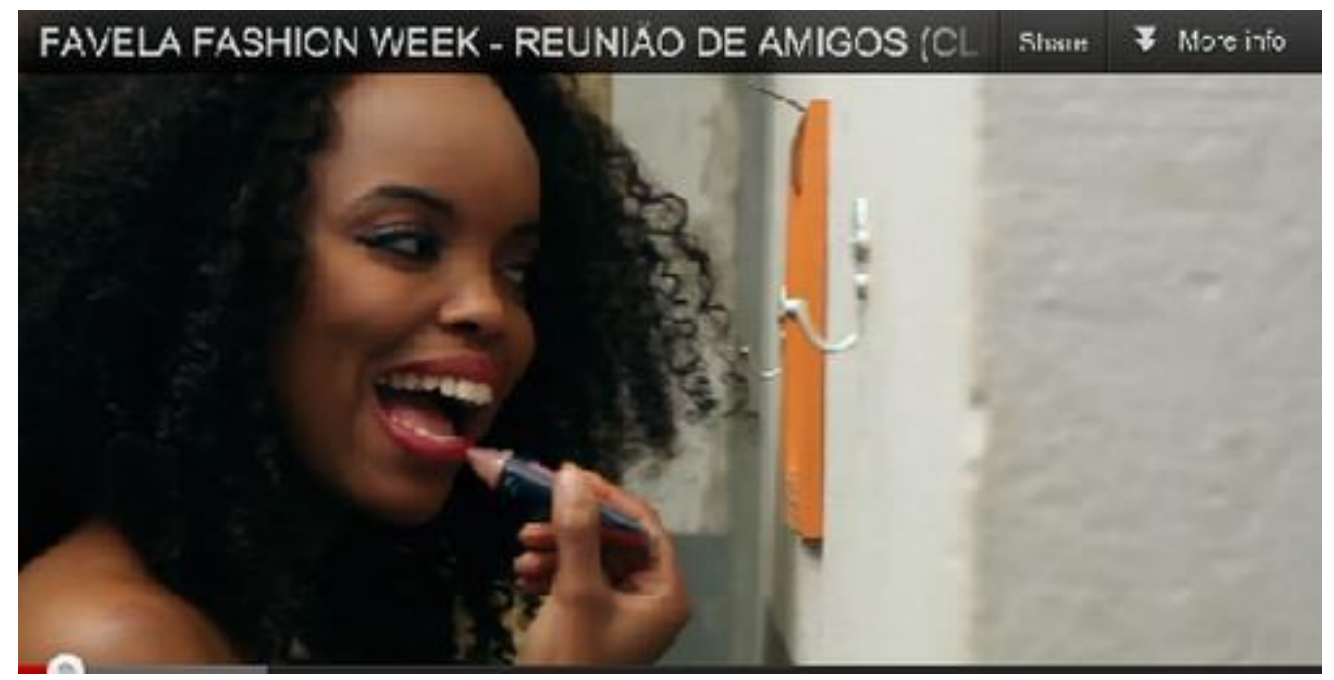

Disponível em http://www.vozdascomunidades.com.br/videos/favela-fashion-week-reuniao-deamigos-clipe-oficial

Alguém bate à porta e informa à jovem, Gisele, que ela tem apenas cinco minutos para dar início ao desfile. Em seguida, há um outro corte brusco e a tomada externa passa a focalizar, em plano mais amplo, uma rua da favela, alguns moradores, ambulantes, alguém andando de bicicleta. A essas imagens somam-se, em uma relação parafrástica, ruídos que lembram o cotidiano da favela: cães latindo, vozes distantes. Em um novo corte, em uma tomada de cima, em plano aberto, aparecem as casas da 
favela, em primeiro plano, tendo, ao fundo, quase indistintos, os edifícios e a skyline da cidade. Mais uma vez, a diferença se marca, desta vez no plano arquitetônico.

Há uma relação significante entre as tomadas externas que retratam o cotidiano da favela e a cena do camarim, onde algo novo se anuncia. No camarim, a imagem da Gisele loura, rica, conhecida internacionalmente, ícone de elegância, beleza e sex appeal sai de cena e é substituída pela da Gisele negra, linda, magra e elegante. Esse jogo, no entanto, pela sequência de imagens e pela relação entre os objetos cenográficos - a fotografia da Gisele loura e o espelho em que a Gisele negra se olha - sugere uma relação parafrástica e tem um efeito irônico, debochado. É justamente esta ironia diante da contradição e da incompletude evidenciada pelas imagens que, mais uma vez, evidenciará o processo discursivo. A sobreposição das imagens sugerida pela sequência faz trabalhar uma rede de memória que evoca as tentativas de europeização e o embranquecimento da população, que continuam mobilizando sentidos no verbal e no visual, mas que aqui trazem a marca da contradição, evidenciada pela ironia, pela inversão.

É desse modo que o padrão de beleza do mundo da moda é reapresentado/narrado com outros sentidos, aberto a novos tipos, na letra da música exibida no clipe: "tem para todos os gostos, gordinha, sarada e magrela". Nesse ponto, o verbal e o imagético funcionam em relação de parafrasagem, com letra e imagem marcando não a integração entre o morro e o asfalto, mas a diferença.

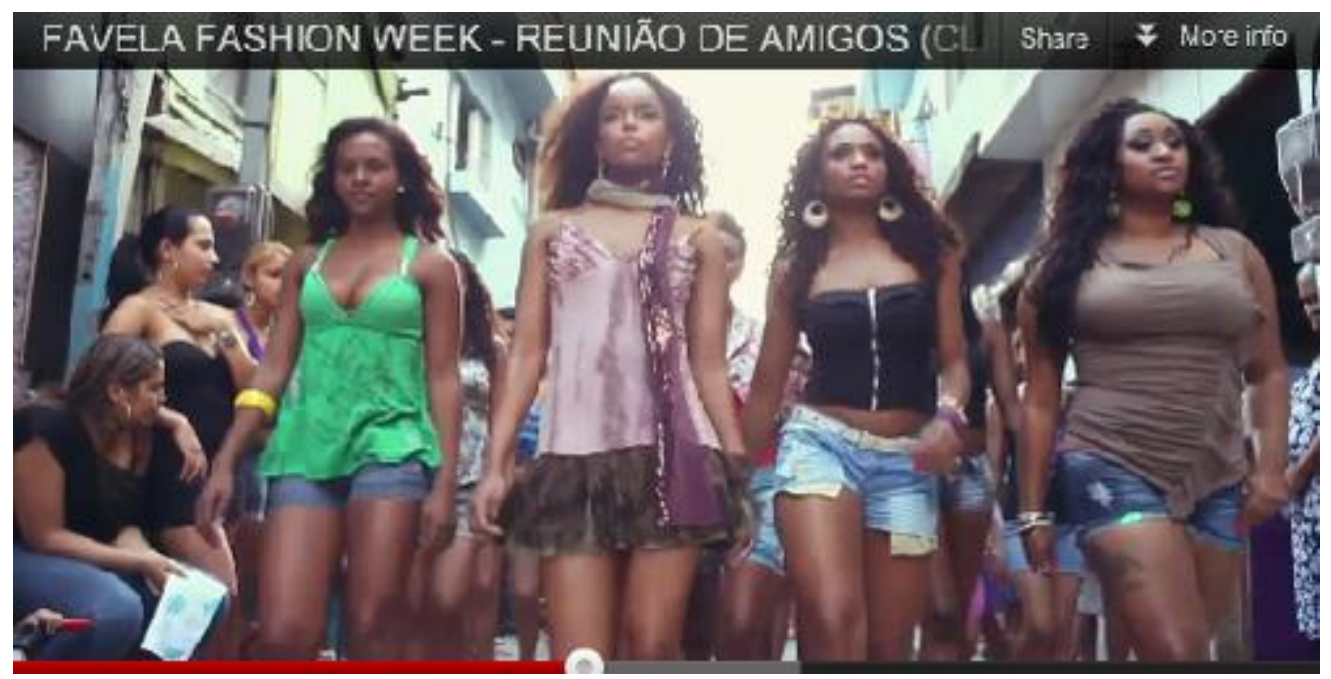

Disponível em http://www.vozdascomunidades.com.br/videos/favela-fashion-week-reuniao-deamigos-clipe-oficial 
O desfile na favela ocorre no verão (o evento São Paulo Fashion Week é no inverno), os tipos de mulheres bonitas são mais variados - "tem para todos os gostos". A passarela se estende por toda a favela. Observa-se então o discurso da valorização do morro, através de uma comparação que coloca a favela como tendo muito mais mulheres bonitas do que os desfiles das esquálidas branquelas do asfalto. Deslocando-se do rosto ao corpo das meninas, em closes insinuantes, a câmera marca a diferença entre o corpo da mulher do morro e a do asfalto, retomando uma memória do corpo da mulher negra que atraia o homem branco pela sensualidade e apelo sexual. Da mesma forma, a diferença é marcada esteticamente na vestimenta das meninas: shorts curtos, tops decotados, cores vibrantes, sapatos bem altos.

Os gestos de des-interpretação da favela como espaço restrito à pobreza, à criminalidade permeiam a tessitura do vídeo. Já no início do desfile, a Gisele negra descarta uma garrafa de água mineral jogando-a em uma lixeira guardada por um gari. Cena aparentemente incidente e banal, que será retomada no final do vídeo, com o gari caminhando e carregando a lixeira pela viela limpa, mas que reconfigura o imaginário sobre a favela no que diz respeito ao lixo e aos hábitos higiênicos de seus moradores.

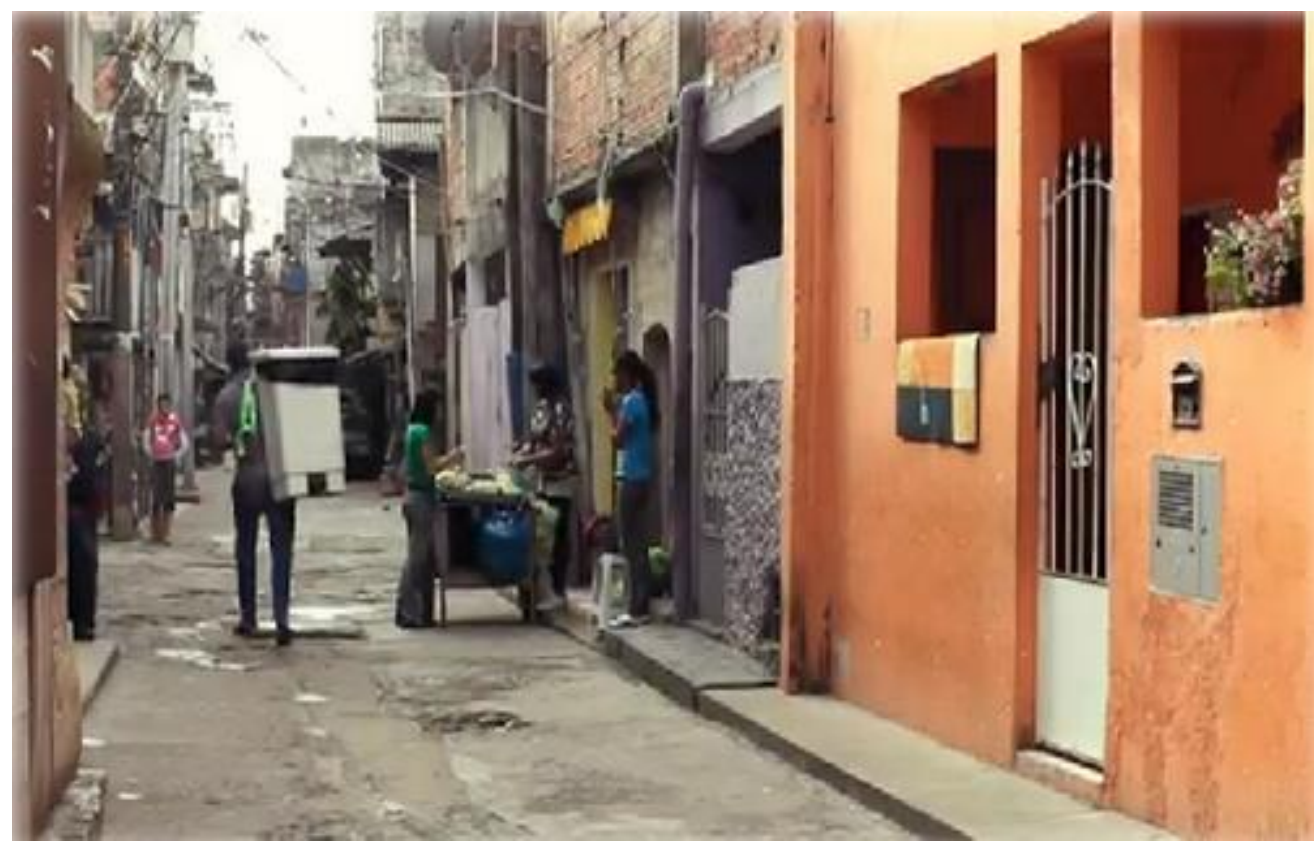

Disponível em http://www.vozdascomunidades.com.br/videos/favela-fashion-week-reuniao-deamigos-clipe-oficial 
$\mathrm{Na}$ letra da música, a inversão e a consequente des-interpretação da favela como espaço de droga e criminalidade se revelam nos deslizamentos de sentidos já regularizados:

\section{Favela Fashion Week ${ }^{2}$}

Claytinho Persona, Nego Branco, Manu

O verão na favela parece um desfile de moda

A viela vira passarela

O bagulho é fora

do comum

Cada peitinho, cada bumbum

Na descida do morro a rapa escolhe a mais bela

Tem pra todos os gostos, gordinha, sarada e magrela

É um zum, zum, zum

e na plateia eu sou mais um

No Carrão, no Capão, Guacuri, Paquistão e na Vila Prudente

tá assim de modelo, aspirante a miss

São várias pretendentes

Cantagalo, Mangueira, Rocinha, Alemão e Cidade de Deus

Tem gente desfilando

eu só fico olhando

o jurado sou eu

Nosso morro é coisa chique

é Favela Fashion Week

Sobe lá pra você ver

Nosso morro é muita treta

nossa Gisele Bundchen é preta

e ela faz acontecer

O termo "bagulho", frequentemente relacionado à droga, à coisa ruim, à mulher feia, em "o bagulho é fora do comum" na letra da música é reinterpretado positivamente como algo fora de série. Da mesma forma, "treta", geralmente associado à malandragem e à trapaça é, como atributo para o morro, ressignificado positivamente como descolado, legal, bacana 'nosso morro é muita treta'. Na imagem, os sentidos convergem na construção dessa positividade. Ao chegar ao final da passarela, as meninas, sempre alegres e sorridentes, passam a sambar, juntando-se aos espectadores que as aplaudem e cantam o samba com o grupo Reunião de Amigos.

\section{Resistência e memória}

A narrativa urbana que analisamos, como já dissemos, ao reconfigurar ideológica e politicamente o espaço da favela e as práticas sociais a ele relacionadas,

\footnotetext{
${ }^{2}$ Disponível em http://www.vagalume.com.br/reuniao-de-amigos/favela-fashion-week.html
} 
traz, em sua materialidade, tanto as marcas das expectativas do sujeito diante do devir quanto as marcas de sua resistência às ameaças que sofre em seus processos de memória.

A “des-interpretação" produzida nas discursividades que redesenham o espaço e a cultura é, como observa Mariani (2009, p.45-46), resultado de práticas de sujeitos e entre sujeitos, "não dissociadas dos modos sócio-históricos de produção, reprodução, resistência e transformação dos sentidos. Práticas expostas também à errância e à não totalidade dos processos de significação".

Neste ponto retomamos a observação feita no início do texto, a partir de Orlandi (2004, p.12), sobre a "abertura do simbólico", constitutiva dos sistemas significativos que operam neste vídeo e que têm a incompletude e a contradição como marcas da relação da materialidade significante com a história e a memória. "Dá uma olhada na descida do morro", diz a música para um destinatário que está no asfalto. Mais adiante, no que parece ser uma inserção de comentários paralelos à letra da música, o sujeito corporificado na figura do cantor, convidando o interlocutor/espectador a olhar mais atentamente as meninas, anuncia "daqui não saio, daqui ninguém me tira", um gesto que marca, na linguagem, a resistência do sujeito às ameaças aos seus processos de memória. Evidencia-se, portanto, na opacidade da linguagem, a contradição do discurso de integração sugerido por uma primeira expectativa em relação ao vídeo, e por sua relação com outros enunciados que compõem o Portal Voz das Comunidades. Lembramos, a respeito dessa relação interdiscursiva, que, em um primeiro momento, pensávamos que as locações do vídeo teriam sido feitas nas comunidades cariocas que integram o Portal Voz das Comunidades. Para nossa surpresa, as locações foram feitas em Vila Prudente, favela de São Paulo. Nomeando favelas paulistas e cariocas - "No Carrão, no Capão, Guacuri, Paquistão e na Vila Prudente (...) Cantagalo, Mangueira, Rocinha, Alemão e Cidade de Deus" -, a letra da música sublinha de forma destacada este efeito de sentido sobre o urbano que não individualiza a favela. Muito pelo contrário, o que é realçado são os traços culturais comuns a todas as favelas e seus moradores e que os distinguem dos moradores do asfalto.

Vale observar que, nessa perspectiva, a fragmentação sugerida pelas tomadas externas iniciais, que retratam o cotidiano da favela, e as sequências do camarim, vai ser retomada, de forma invertida na sequência final do clipe, quando a viela será novamente mostrada. O gari leva a lixeira nas costas, os cachorros latem e vozes ecoam na distância. $\mathrm{O}$ efeito de sentido obtido no corte abrupto na montagem do vídeo, tanto no 
início, quanto no final, sugere a irrupção de um acontecimento extraordinário, talvez um sonho, que chega ao fim depois de interromper e congelar no tempo o cotidiano e o vai e vem dos moradores.

\section{Concluindo}

No vídeo que examinamos, a janela de que se olha a favela se abre para se dar a conhecer a quem não está nela. O verbal, o imagético e a melodia do samba operando na incompletude que lhes é constitutiva compõem, na imbricação de suas materialidades, um discurso marcado pela contradição, pelo equívoco. A favela é ressignificada para um outro olhar, o olhar de quem está de fora. Orientado por uma visão configurada ideológica e politicamente, o clipe transforma em espaço de convivência, cultura, lazer e consumo lugares pré-configurados nos mapas do imaginário do asfalto como espaços de pobreza, privação e criminalidade. Mesmo havendo um deslocamento nessa reconfiguração do imaginário urbano, o clipe não repete o discurso da inclusão e da integração nem procura a adequação às formas dominantes da cultura. Pelo contrário, embora os efeitos de evidência sugiram esta adequação, o funcionamento do processo discursivo e os efeitos de sentido dele derivados são marcados pela resistência à cultura dominante.

\section{Referências Bibliográficas}

CERTEAU, Michel. 2004. A invenção do cotidiano - Artes de fazer. Petrópolis: Vozes. GONDAR, Jô. 2005. Quatro proposições sobre memória social. In: Gondar, Jô; Dodebei, Vera (orgs.). O que é memória social. Rio de Janeiro: Contracapa.

JACQUES, Paola Berenstein. 2001. Estética das favelas. Arquitextos, São Paulo, 02.013, Vitruvius, jun. Disponível em:

http://www.vitruvius.com.br/revistas/read/arquitextos/02.013/883.

JEUDY, Henri-Pierre. 2005. Espelho das cidades. Rio de Janeiro: Casa da Palavra.

LAGAZZI, Suzy. 2009. O recorte significante na memória. In: Indursky, Freda; Ferreira, Maria Cristina Leandro; Mittman, Solange (orgs.). $O$ discurso na contemporaneidade.Materialidades e fronteiras. São Carlos: Claraluz.

MARIANI, Bethania. 2009. Sujeito e discursos contemporâneos. In: Indursky, Freda; Ferreira, Ma. Cristina Leandro; Mittman, Solange. (orgs.) $O$ discurso na contemporaneidade. Materialidades e fronteiras. São Carlos: Claraluz. p. 43-52. 
1998. O PCB e a imprensa. Os comunistas no imaginário dos jornais: 19221989. Campinas: Unicamp/Revan.

ORLANDI, Eni. 2004. Interpretação. Autoria, leitura e efeitos do trabalho simbólico. Campinas: Pontes.

2001. Tralhas e troços: o flagrante urbano. In:

(org.) Cidade atravessada. Os sentidos públicos no espaço urbano. Campinas: $\overline{\text { UNICAMP. }}$

PÊCHEUX, Michel. 2002. O Discurso. Estrutura ou acontecimento. Campinas: Pontes. . 1999. Papel da memória. In: Achard, Pierre et al. Papel da memória. Campinas: Pontes. 
Para citar essa obra:

FERREIRA, L. M. A.; RODRIGUES, A. Memória, narrativa urbana e favela: efeitos de sentido em um videoclipe. In: RUA [online]. 2014, no. 20. Volume 1 - ISSN 1413-2109. Consultada no Portal Labeurb - Revista do Laboratório de Estudos Urbanos do Núcleo de Desenvolvimento da Criatividade

http://www.labeurb.unicamp.br/rua/

Capa: Print do videoclipe "Favela Fashion Week". Disponível em:

www.vozdascomunidades.com.br/videos/favela-fashion-week-reuniao-de-amigos-clipeoficial

Laboratório de Estudos Urbanos - LABEURB

Núcleo de Desenvolvimento da Criatividade - NUDECRI

Universidade Estadual de Campinas - UNICAMP

http://www.labeurb.unicamp.br/

Endereço:

LABEURB - LABORATÓRIO DE ESTUDOS URBANOS

UNICAMP/COCEN / NUDECRI

CAIXA POSTAL 6166

Campinas/SP - Brasil

CEP 13083-892

Fone/ Fax: (19) 3521-7900

Contato: http://www.labeurb.unicamp.br/contato 